\title{
A confusing patient's history: small or large vessel vasculitis?
}

\author{
Nathan Cantoni · Peter Meyer · Mira Katan · \\ Ludwig Kappos · Christoph Hess · Thomas Daikeler
}

Received: 1 July 2009/Accepted: 13 September 2009/Published online: 23 September 2009

(C) Springer-Verlag 2009

\section{Case report}

We report on a 59-year-old patient, referred for sudden visual loss of both eyes. The patient reported blurred vision and conjunctivitis of the left eye since a few days. Additionally fatigue, weight loss $(3 \mathrm{~kg})$, night sweats, myalgia, difficulties in hearing on the right ear, frontal headache and pain while chewing (claudicatio masticatoria) since 2 weeks were reported.

The initial ophthalmological examination revealed a visus of 0.1 on both sides, conjunctivitis was confirmed and funduscopy revealed ischemic retinal lesions with multiple peripapillary cotton-wool spots (CWS) (Fig. 1). Routine laboratory studies showed thrombocytosis with

N. Cantoni $(\bowtie)$

Division of Hematology, University Hospital Basel,

4 Petersgraben, 4031 Basel, Switzerland

e-mail: ncantoni@uhbs.ch

\section{P. Meyer}

Institute of Pathology, University Hospital Basel,

Basel, Switzerland

M. Katan · L. Kappos

Division of Neurology, University Hospital Basel,

Basel, Switzerland

C. Hess

Medical Outpatient Department, University Hospital Basel,

Basel, Switzerland

T. Daikeler

Division of Rheumatology, University Hospital Basel,

Basel, Switzerland
$505 \times 10^{9}$ per L (normal range $150-450 \times 10^{9}$ per L), an increase of the leukocyte count to $15.9 \times 10^{9}$ per $\mathrm{L}$ (normal range $3.5-10.0 \times 10^{9}$ per L), an elevated blood sedimentation rate (BSR) $80 \mathrm{~mm} / \mathrm{h}$ (normal range 0 $19 \mathrm{~mm} / \mathrm{h}$ ) and a C-reactive protein (CRP) of $152 \mathrm{mg} / \mathrm{L}$ (normal range $<10.0 \mathrm{mg} / \mathrm{L}$ ). Cranial MRI was compatible with mastoiditis on the right side and otherwise normal.

Due to the history, the clinical and laboratory findings and the results of the fundoscopy, giant cell arteritis (GCA) was diagnosed according to American College of Rheumatology (ACR) criteria [1], and a steroid therapy with prednisone $1 \mathrm{mg} / \mathrm{kg}$ once daily was initiated. However, biopsy results of the temporal artery were unremarkable. Since mastoiditis and conjunctivitis are not typical findings in GCA, additional tests, including anti-neutrophilic cytoplasmatic antibodies (ANCA) were performed, showing a c-ANCA titer of 1:640 (normal <1:20) and an anti-proteinase 3 (PR3-ANCA) ELISA value of $94 \mathrm{U} / \mathrm{mL}$ (normal $<2.5 \mathrm{U} / \mathrm{mL}$ ). A subsequent pulmonary CT scan documented multiple small nodules. In light of these findings the diagnosis had to be revised to Wegener's granulomatosis (WG) presenting with conjunctivitis, retinal vasculitis, mastoiditis, headache, myalgia, and pulmonary granuloma [2]. A biopsy of the conjunctiva confirmed a chronic granulomatous inflammation consistent with the clinical diagnosis of WG. Therapy was intensified with cyclophosphamide $15 \mathrm{mg} / \mathrm{kg}$ i.v. every 3 weeks for a total of six pulses. The patient improved, ANCA titers fell and a follow-up CT scan 6 months after diagnosis showed complete resolution of the pulmonary granuloma. The patient is with exception of a residual vision loss (visus of 0.7 ), asymptomatic and currently on azathioprine maintenance therapy. The CWS and the retinal edema disappeared. 
Fig. 1 Nodular conjunctivitis of the left eye without associating episcleritis/scleritis (a, b). Fundoscopy (c) and fluorescein angiogram (d) with ischemic retinal lesion with multiple peripapillary cottonwool spots $(C W S)$ on the right eye. Fundoscopy (e) and fluorescein angiogram (f) of the left eye with retinal edema
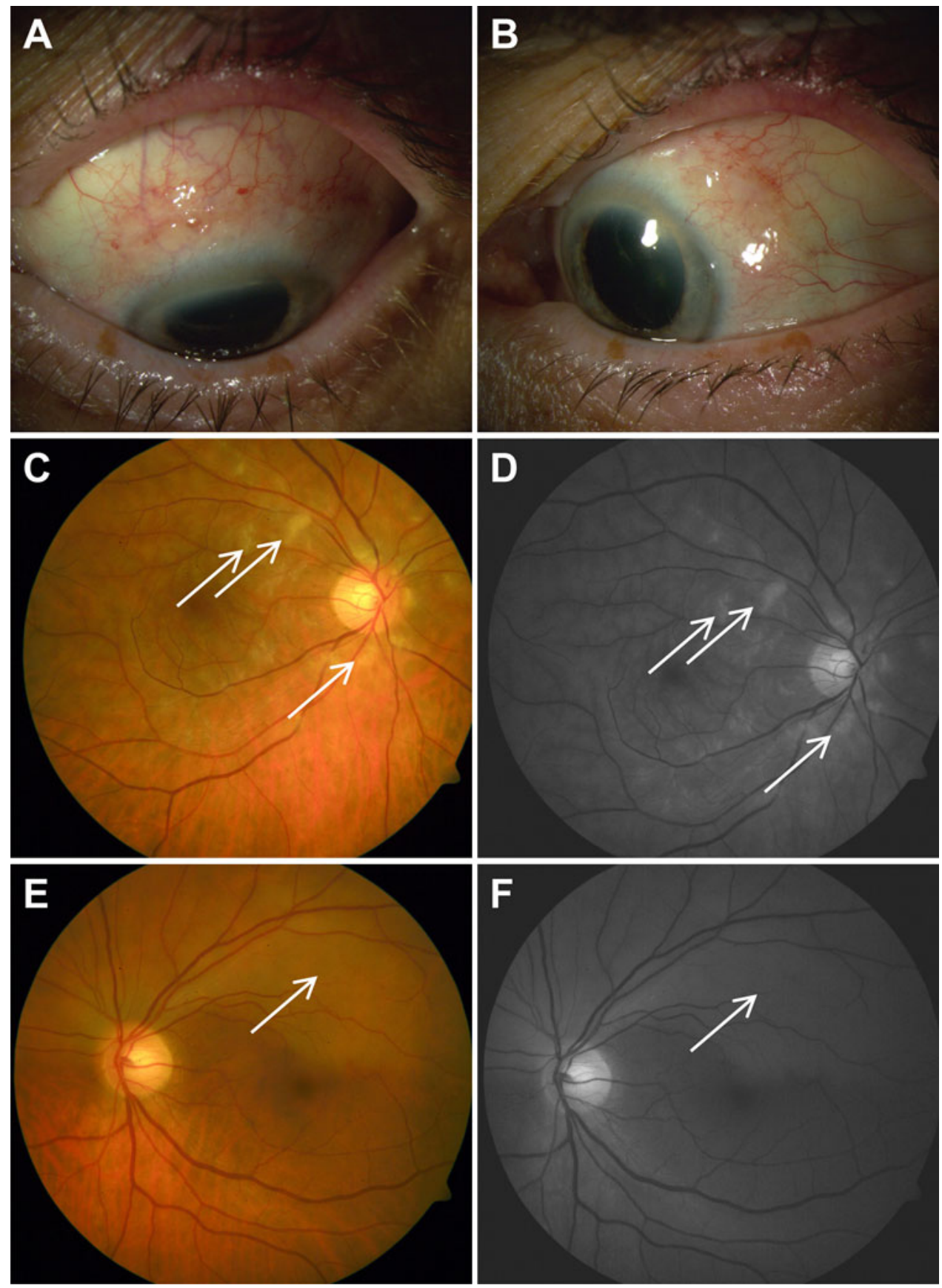

\section{Comment}

This case nicely demonstrates that the diagnosis of WG can be puzzling [3]. In our patient GCA was the most obvious diagnosis. However, the presence of mastoiditis and conjunctivitis as well as the normal histology of the temporal artery were reason to question the diagnosis. A positive PR3 ANCA was the clue for diagnosing WG. The patients' ischemic symptoms may have been due to necrotizing vasculitis of the temporal arteries as it has been previously reported [4], or due to vasculitis of smaller vessels supplying eye and the masseter muscle. Because of the normal histology of the temporal artery, the latter was more likely the case.

Granulomatous conjunctivitis without affection of the sclera as well as ischemic retinal lesions due to arterial occlusions are rare manifestations of WG [5-7]. In only one patient with WG reported in the literature arterial occlusion was associated with symptoms of GCA [7].

Thus, in our patient a rare retinal manifestation of a small vessel vasculitis mimicked a large vessel vasculitis, reminding us that WG has to be considered as a differential diagnosis in atypical GCA. 


\section{References}

1. Hunder GG, Bloch DA, Michel BA et al (1990) The American College of Rheumatology 1990 criteria for the classification of giant cell arteritis. Arthritis Rheum 33:1122

2. Leavitt RY, Fauci AS, Bloch DA et al (1990) The American College of Rheumatology 1990 criteria for the classification of Wegener's granulomatosis. Arthritis Rheum 33:1101

3. Reinhold-Keller E, Beuge N, Latza U et al (2000) An interdisciplinary approach to the care of patients with Wegener's granulomatosis: long-term outcome in 155 patients. Arthritis Rheum 43:1021
4. Miller NR (2001) Visual manifestations of temporal arteritis. Rheum Dis Clin North Am 27(4):781-797

5. Harman LE (1998) Wegener's granulomatosis (review). Surv Ophthalmol 42:458-480

6. Toh TY (2006) Wegener's granulomatosis presenting with painless bulbar-conjunctival ulcer and retinal artery occlusion. Clin Exp Opthalmol 34:51-53

7. Lamprecht $P$ et al (2000) Retinal artery occlusion in Wegener's granulomatosis. Rheumatology 39:928-929 